\title{
EFEKTIVITAS PENGOLAHAN LIMBAH CAIR DOMESTIK DENGAN MENGGUNAKAN MEDIA TUTUP GALON BEKAS
}

The Effectiveness Of Domestic Waste Water Treatment Using Used Gallon Cap Media Muh. Fajaruddin Natsir ${ }^{1}$, Amaludin ${ }^{1}$, Astisa Anggi Liani ${ }^{1}$, Anzakiyah Dwi Fahsa',

\author{
Desi Marlina² \\ ${ }^{1}$ Fakultas Kesehatan Masyarakat Universitas Hasanuddin \\ ${ }^{2}$ Kantor Kesehatan Pelabuhan Makassar \\ *) fajarnatsir@unhas.ac.id
}

\begin{abstract}
Waste Water is a very potential source of water pollution because it contains quite high compounds, and other chemical compounds and pathogenic microorganisms that are harmful to health, so it needs to be treated first before being discharged into water bodies. This study aims to determine the effectiveness of domestic wastewater treatment using used gallon cap media on biofilters in reducing BOD and TSS levels in domestic wastewater. This research is quasi experiment with Pretest-Posttest Design. The research started with literature review, biofilter manufacture, media preparation, and core research, namely biofilter testing. The results showed that after using a gallon cap media biofilter, the BOD parameter decreased from $186.75 \mathrm{mg} / \mathrm{L}$ to $6.31 \mathrm{mg} / \mathrm{L}$ with an efficiency of $97 \%$. As for the TSS parameter from $81.65 \mathrm{mg} / \mathrm{L}$ to $3 \mathrm{mg} / \mathrm{L}$ with a reduction efficiency of $94 \%$. Waste water treatment using a used gallon cap media biofilter is proven to be effective in reducing BOD and TSS parameters according to quality standards based on the Regulation of the Minister of Environment and Forestry of the Republic of Indonesia Number 68 of 2016 concerning Domestic Wastewater Quality Standards.

Keywords : Biofilter, Used Gallon Cap, Waste water
\end{abstract}

\section{ABSTRAK}

Limbah cair merupakan sumber pencemaran air yang sangat potensial karena mengandung senyawa yang cukup tinggi, dan senyawa kimia lain serta mikroorganisme patogen yang berbahaya bagi kesehatan sehingga perlu dilakukan pengolahan terlebih dahulu sebelum di buang ke badan air. Penelitian ini bertujuan untuk mengetahui efektivitas pengolahan limbah cair domestik dengan menggunakan media tutup galon bekas pada biofilter dalam mereduksi parameter BOD dan TSS limbah cair domestik. Penelitian ini bersifat quasi eksperimen dengan rancangan PretestPostest Design. Penelitian dimulai dengan kajian literatur, pembuatan biofilter, penyiapan media, dan penelitian inti yaitu pengujian biofilter. Hasil penelitian menunjukkan bahwa setelah dilakukan dengan menggunakan biofilter media tutup galon didapatkan penurunan untuk parameter BOD dari 186,75 mg/L menjadi 6,31 mg/L dengan efisiensi sebesar $97 \%$. Sedangkan untuk parameter TSS dari 81,65 mg/L menjadi $3 \mathrm{mg} / \mathrm{L}$ dengan efisiensi penurunan sebesar $94 \%$. Pengolahan limbah cair dengan menggunakan biofilter media tutup galon bekas terbukti efektif menurunkan parameter BOD, dan TSS sesuai baku mutu berdasarkan Peraturan Menteri Lingkungan Hidup dan Kehutanan RI Nomor 68 Tahun 2016 Tentang Baku Mutu Air Limbah Domestik.

Kata kunci :Biofilter, Tutup Galon Bekas, Limbah Cair

\section{PENDAHULUAN}

Pencemaran air masih menjadi masalah di negara kita. Kontribusi terbesar dari pencemaran air ini berasal dari limbah cair domestik. Untuk wilayah Jakarta, kontribusi terbesar limbah dari segi kuantitas terhadap pencemaran yaitu $75 \%$ berasal domestic, 15 $\%$ berasal dari perkantoran dan daerah komersial, sisanya $10 \%$ berasal dari industry. Sedangkan apabila dilihat dari beban polutan organiknya, sumber pencemaran terbesar 70 $\%$ domestik, 16\% berasal dari industri, dan 14 $\%$ berasal dari perkantoran (Said, 2011).

Upaya untuk menurunkan kandungan bahan organik pada limbah cair baik dari industri maupun rumah tangga telah banyak dilakukan, diantaranya menggunakan metode fisika-kimia (Nugti et al., 2020), biologis anaerob dan aerob (Luo et al., 2014; Rasool et al., 2018; Natsir and Selomo, 2020), dan pemanfaatan tanaman air (fitoremediasi) (Valipour, Raman and Ghole, 2011; Elfanssi et al., 2018). Akan tetapi, penerapan ketiga metode tersebut dalam skala rill relatif sulit karena beberapa alasan, antara lain : metode dan operasi relatif kompleks, kebutuhan jumlah koagulan besar, sedangkan untuk pengolahan limbah cair secara biologis aerob memerlukan biaya energi listrik untuk aerasi tinggi, serta lahan pengolahan yang relatif luas. Selain itu, pengolahan limbah cair dengan pemanfaatan tanaman air (fitoremediasi) selain membutuhkan lahan yang luas juga membutuhkan waktu lama. Dengan demikian, para masyarakat sering membuang limbah ke badan air tanpa pengolahan terlebih dahulu. Oleh karena itu, teknologi yang tepat dan aman serta relatif murah harus diterapkan dalam upaya penanganan limbah cair.

Bioflter merupakan salah satu metode pengolahan limbah cair secara biologi. Pengolahan limbah cair dengan metode ini yaitu dengan memanfaatkan mikroorganisme yang melekat pada media biofilter tersebut. Mikrooganisme ini berfungsi untuk mereduksi bahan-bahan pencemar yang ada pada air limbah. 
Jurnal Sulolipu : Media Komunikasi Sivitas Akademika dan Masyarakat

Vol. 21 No.2 2021

e-issn : 2622-6960, p-issn : 0854-624X

Beberapa penelitian mendapatkan hasil yang cukup baik dalam mereduksi beberapa parameter dengan menggunakan metode ini. Persentase removal parameter TSS dengan menggunakan metode ini berada pada kisaran $70 \%-95 \%$ (Noor Suraya and Nadiah, 2011; Zahra, 2015; Natsir et al., 2019; Natsir and Selomo, 2020)

Untuk parameter BOD, metode pengolahan limbah cair dengan metode bifilter juga cukup efektif. Beberapa penelitian yang menggunakan metode ini mendapatkan hasil penurunan BOD $45-94 \% \%$ (Noor Suraya and Nadiah, 2011; Garkal, Mapara and Prabhune, 2015; Zahra, 2015; Natsir et al., 2019; Natsir and Selomo, 2020).

Perbedaan variasi hasil penurunan parameter pencemar dengan menggunakan biofilter dipengaruhi oleh beberapa faktor. Selain waktu kontak air limbah dengan bahan media, penurunan juga dipengaruhi oleh media biofilter yang digunakan. Media biofilter yang umum digunakan adalah yang terbuat dari Polimer, batu kerikil, tali jala, batu apung, dan pipa

Penelitian telah membuktikan bahwa pengolahan limbah cair yang menggunakan media dari bahan plastik mampu menurunkan parameter pencemar yang cukup signifikan. Akan tetapi, penggunaan media dari bahan plastik ini membutuhkan biaya yang cukup besar. Sehingga diperlukan alternative plastik yang murah dan mudah untuk didapat. Salah satu bahan plastik yang mudah dan murah untuk didapatkan adalah tutup gallon bekas. Untuk itu penulis tertarik mengkaji efektivitas pengolahan limbah cair dengan menggunakan media tutup galon bekas.

Penelitian ini sangat penting untuk dilakukan karena hasil dari penelitian ini akan memberikan kontribusi besar terhadap pelestarian lingkungan. Hasil dari penelitian ini akan memberikan model sistem pengolahan limbah cair yang murah dan mudah untuk dilakukan khususnya domestik.

\section{METODE}

\section{Desain, tempat dan waktu}

Penelitian ini menggunakan desain quasi eksperimen untuk mengetahui efektivitas dari pengolahan limbah cair dengan menggunakan tutup galon bekas dalam menurunkan parameter BOD, dan TSS. Rancangan penelitian yang digunakan adalah Pretest-Postest Control Group Design. Kelompok eksperimen pada penelitian ini adalah limbah cair yang dilakukan pengolahan dengan menggunakan biofilter media tutup galon bekas, sedangkan kelompok kontrol adalah limbah cair yang tidak dilakukan pengolahan.

Data pretest diperoleh dari pemeriksaan parameter air limbah sebelum dilakukan pengolahan, sedangkan data posttest setelah dilakukan pengolahan yang diukur selama 7 hari. Penelitian dilakukan pada bulan Agustus-September 2021. Untuk mengetahui efektifitas dari model pengolahan ini maka hasil pengukuran yang didapatkan akan di bandingkan dengan Peraturan Menteri Lingkungan Hidup dan Kehutanan RI Nomor P.68 Tahun 2016 Tentang Baku Mutu Air Limbah Domestik.

Pemeriksaan kadar BOD, dan TSS dilakukan di Laboratorium Kimia Biofisik FKM Unhas. Analisis $\mathrm{pH}$ dan temperature dilakukan secara insitu menggunakan $\mathrm{pH}$ meter dan thermometer air raksa. Analisa data dilakukan secara deskriptif, yang digambarkan melalui tabel, grafik dan narasi

\section{HASIL}

Tabel 1 memperlihatkan hasil pengukuran $\mathrm{pH}$ dan Suhu dari air limbah pada sampel eksperimen dan kontrol. Hasil pengukuran parameter suhu berada pada rentang 26,3-32,8, dengan rata-rata suhu pada sampel eksperimen adalah $31,9^{\circ} \mathrm{C}$ dan pada sampel kontrol adalah $28,5^{\circ} \mathrm{C}$. Sedangkan untuk parameter $\mathrm{pH}$ berada pada rentang 6,727,89 dengan rata-rata $\mathrm{pH}$ pada sampel eksperimen adalah 7,19 dan pada sampel kontrol 7,38

Tabel 2 memperlihatkan hasil pengukuran BOD dari air limbah pada sampel eksperimen dan kontrol. Efiseinsi penurunan BOD pada hari 7 untuk sampel eksperimen sebesar $97 \%$ dan pada sampel kontrol sebesar 84 \%. Grafik 2 memperlihatkan bahwa biofilter media tutup galon bekas mampu menurunkan parameter BOD pada hari ke 4, sedangkan air limbah tanpa pengolahan memenuhi baku mut yang diperbolehkan pada hari ke 7.

Tabel 3 memperlihatkan hasil pengukuran TSS dari air limbah pada sampel eksperimen dan kontrol. Efiseinsi penurunan TSS pada hari 7 untuk sampel eksperimen sebesar $94 \%$ dan pada sampel kontrol sebesar 80 \%. Grafik 3 memperlihatkan bahwa biofilter media tutup galon bekas mampu menurunkan parameter TSS pada hari ke 3, sedangkan air limbah tanpa pengolahan memenuhi baku mutu yang diperbolehkan pada hari ke 5 . 
Jurnal Sulolipu : Media Komunikasi Sivitas Akademika dan Masyarakat

Vol. 21 No.2 2021

e-issn : 2622-6960, p-issn : 0854-624X

\section{PEMBAHASAN}

Pengolahan limbah cair dilakukan untuk menghilangkan unsur-unsur pencemar dari air limbah sehingga ketika dibuang ke lingkungan memenuhi baku mutu dan tidak mencemari lingkungan sekitar. Instalasi Pengolahan Limbah Domestik dibangun dengan maksud untuk mengolah limbah cair yang dihasilkan oleh rumah tangga misalnya yang bersumber kamar mandi, air sisa dapur, air sisa cucian dll.

Penelitian ini merupakan penelitian quasi eksperimen yang membandingkan antara pengolahan limbah cair sistem biofilter dengan menggunakan tutup galon bekas sebagai media penumbuhan biofilm dan limbah cair ditampung saja tanpa pengolahan. Parameter yang diteliti adalah Biological Oxygen Demand (BOD), dan Total Suspended Solid (TSS), serta parameter tambahan adalah $\mathrm{pH}$ dan suhu.

Parameter yang di teliti dibandingkan dengan baku mutu yang telah ditetapkan. Baku mutu yang digunakan adalah berdaarkan Peraturan Menteri Lingkungan Hidup dan Kehutanan RI Nomor P.68 Tahun 2016 Tentang Baku Mutu Air Limbah Domestik.

Suhu air limbah selama proses pengolahan berada pada kisaran $26,3-32,8^{\circ} \mathrm{C}$ dengan rata-rata suhu pada sampel eksperimen adalah $31,9^{\circ} \mathrm{C}$ dan pada sampel kontrol adalah $28,5^{\circ} \mathrm{C}$. Suhu air limbah ini masih berada pada rentang suhu yang baik untuk penumbuhan mikroorganisme yaitu berkisar $25-35^{\circ} \mathrm{C}$.

Parameter $\mathrm{pH}$ berada pada rentang 6,72-7,89 dengan rata-rata $\mathrm{pH}$ pada sampel eksperimen adalah 7,19 dan pada sampel kontrol 7,38. Parameter pH Suhu air limbah ini masih berada pada rentang $\mathrm{pH}$ optimum bagi bakteri untuk beraktivitas.

Hasil pengukuran parameter BOD dari limbah cair baik yang setelah dilakukan pengolahan dengan biofilter media tutup galon bekas maupun tanpa pengolahan mengalami penurunan. Batas maksimum yang diperbolehkan untuk parameter BOD air limbah domestik berdasarkan Peraturan Menteri Lingkungan Hidup dan Kehutanan RI Nomor P.68 Tahun 2016 Tentang Baku Mutu Air Limbah Domestik adalah adalah $30 \mathrm{mg} / \mathrm{l}$. Sebelum air limbah masuk ke Biofilter, ratarata kandungan BOD air limbah pada sampel eksperimen dan kontrol adalah sebesar 186,75 $\mathrm{mg} / \mathrm{L}$. Efisiensi penurunan BOD pada hari ke 7 untuk sampel eksperimen adalah $97 \%$ sedangkan pada kontrol sebesar $84 \%$. Dari grafik 2 memperlihatkan bahwa biofilter media tutup galon bekas mampu menurunkan parameter BOD pada hari ke 4 , sedangkan air limbah tanpa pengolahan memenuhi baku mutu yang diperbolehkan pada hari ke 7 . Hal ini berarti bahwa kandungan BOD setelah dilakukan pengolahan pada eksperimen lebih baik dibandingkan pada kontrol.

Penelitian ini sejalan beberapa hasil penelitian yang juga mendapatkan hasil yang efektif dalam menurunkan parameter BOD dengan menggunakan biofilter. Misalnya penelitian yang dilakukan untuk mengolah air limbah domestik di Rusunawa Unhas mendapatkan efisiensi sebesar 82,26 (Bahar, Tawali and Muin, 2013). Penelitian lain yang menggunakan biofilter dalam mengolahan limbah cair mendapatkan sebesar 72,05\% (Garkal, Mapara and Prabhune, 2015). Penelitian lain yang sejalan juga dengan penelitian ini adalah penelitian yang menggunakan media papan pakis yang mendapatkan efisiensi sebesar $65,49 \%$ (Mangiri, 2019).

Hasil pengukuran parameter TSS dari limbah cair baik yang setelah dilakukan pengolahan dengan biofilter media tutup galon bekas maupun tanpa pengolahan mengalami penurunan. Batas maksimum yang diperbolehkan untuk parameterTSS air limbah domestik berdasarkan Peraturan Menteri Lingkungan Hidup dan Kehutanan RI Nomor P.68 Tahun 2016 Tentang Baku Mutu Air Limbah Domestik adalah adalah $30 \mathrm{mg} / \mathrm{l}$. Sebelum air limbah masuk ke Biofilter, ratarata kandungan TSS air limbah pada sampel eksperimen dan kontrol adalah sebesar 81,65 $\mathrm{mg} / \mathrm{L}$. Efisiensi penurunanTSS pada hari ke 7 untuk sampel eksperimen adalah $94 \%$ sedangkan pada kontrol sebesar $80 \%$. Dari grafik 3 memperlihatkan bahwa biofilter media tutup galon bekas mampu menurunkan parameter TSS pada hari ke 3, sedangkan air limbah tanpa pengolahan memenuhi baku mutu yang diperbolehkan pada hari ke 5 . Hal ini berarti bahwa kandungan TSS setelah dilakukan pengolahan pada eksperimen lebih baik dibandingkan pada kontrol.

Penelitian ini sejalan dengan beberapa penelitian yang menggunakan biofilter untuk parameter TSS. Penelitian yang dilakukan di Rusunawa Unhas mendapatkan penurunan dari $38,8 \mathrm{mg} / \mathrm{L}$ menjadi $7,2 \mathrm{mg} / \mathrm{L}$ dengan penurunan sebesar $81,44 \mathrm{mg} / \mathrm{L}$ (efisiensi 81,44\%) (Bahar, Tawali and Muin, 2013). Penelitian lain yang menggunakan biofilter dalam menurunkan parameter TSS menambahkan EM4 untuk mempercepat 
Jurnal Sulolipu : Media Komunikasi Sivitas Akademika dan Masyarakat

Vol. 21 No.2 2021

e-issn : 2622-6960, p-issn : 0854-624X

proses penumbuhan biofilm. Hasil penelitian ini mendapatkan efisiensi penurunan TSS sebesar 73,15\% (Natsir et al., 2019).

Penggunaan biofilter dalam pengolahan limbah cair, juga digunakan dalam mengolah limbah cair rumah sakit. Penelitian ini juga sejalan dengan penelitian yang dilakukan oleh Said yang menggunakan proses biofilter tercelup media sarang tawon dalam mengolah limbah cair rumah sakit mendapatkan efisiensi TSS yang cukup tinggi yaitu $80,0-97,8 \%$ (Said, 2011).

\section{KESIMPULAN}

Pengolahan limbah cair dengan menggunakan biofilter media tutup galon memiliki efisensi penurunan untuk parameter
BOD sebesar $97 \%$ dan TSS sebesar $94 \%$. Pengolahan limbah cair dengan menggunakan biofilter media tutup galon bekas terbukti efektif menurunkan parameter BOD, dan TSS sesuai baku mutu berdasarkan Peraturan Menteri Lingkungan Hidup dan Kehutanan RI Nomor 68 Tahun 2016 Tentang Baku Mutu Air Limbah Domestik

\section{SARAN}

Untuk penelitian selanjutnya, perlu dilakukan inovasi model biofilter yang menggunakan media tutup galon bekas sehingga bisa mempercepat proses pengolahan limbah cair.

\section{DAFTAR PUSTAKA}

Bahar, E., Tawali, A. B. and Muin, M. (2013) 'Spesifikasi dan Efektivitas Peralatan Pengolahan Limbah Cair Domestik Studi Kasus Rusunawa Blok D Universitas hasanuddin', Jurnal Sains dan Teknologi, 13.

Elfanssi, S. et al. (2018) 'Phytoremediation of domestic wastewater using a hybrid constructed wetland in mountainous rural area', International Journal of Phytoremediation, 20(1), pp. 75-87.

Garkal, D., Mapara, J. and Prabhune, M. (2015) 'Domestic Waste Water Treatment By BioFiltration: a Case Study', Journal of Geography and Geology, 4(1), pp. 799-811. Available at: http://www.davidpublisher.org/index.php/Home/Article/index?id=274.html\%5Cnhttp://www.iiste.o rg/Journals/index.php/PPAR/article/view/8740.

Luo, W. et al. (2014) 'Novel two-stage vertical flow biofilter system for efficient treatment of decentralized domestic wastewater', Ecological engineering, 64, pp. 415-423.

Mangiri, S. (2019) 'KEMAMPUAN MEDIA PAPAN PAKIS SEBAGAI BIOFILTER DALAM MENURUNKAN KADAR BOD DAN COD PADA AIR LIMBAH PEMOTONGAN AYAM', Sulolipu: Media Komunikasi Sivitas Akademika dan Masyarakat, 17(2), pp. 93-97.

Natsir, M. F. et al. (2019) 'The Addition Of Effective Microrganism 4 And Charcoal Husk To Biofilter In Domestic Wastewater Treatment In Makassar', in Journal of Physics: Conference Series. IOP Publishing, p. 12105.

Natsir, M. F. and Selomo, M. (2020) 'The effectiveness of drum of wastewater treatment (DOWT) in reducing TSS of domestic wastewater', Enfermeria clinica, 30, pp. 175-177.

Noor Suraya, R. and Nadiah, M. (2011) 'Application of Biofilter System for Domestic Wastewater Treatment', International Journal of Civil Engineering and Geo-Environmental, 2, pp. 13-18.

Nugti, M. A. et al. (2020) 'Uji Efektifitas Koagulan Kapur (CaO), Ferri Klorida (FeCl3), Tawas (Al2 (SO4) 3) Terhadap Penurunan Kadar PO4 dan COD Pada Limbah Cair Domestik (Laundry) Dengan Metode Koagulasi', Proceeding of The URECOL, pp. 345-348.

Rasool, T. et al. (2018) 'Efficiency of a locally designed pilot-scale trickling biofilter (TBF) system in natural environment for the treatment of domestic wastewater', Environmental technology, 39(10), pp. 1295-1306.

Said, N. I. (2011) 'Pengolahan Air Limbah Rumah Sakit Dengan Proses Biologis Biakan Melekat Menggunakan Media Palstik Sarang Tawon', Jurnal Teknologi Lingkungan, 2(3). 
Jurnal Sulolipu : Media Komunikasi Sivitas Akademika dan Masyarakat

Vol. 21 No.2 2021

e-issn : 2622-6960, p-issn : 0854-624X

Valipour, A., Raman, V. K. and Ghole, V. S. (2011) 'Phytoremediation of domestic wastewater using Eichhornia crassipes.', Journal of environmental science \& engineering, 53(2), pp. 183190.

Zahra, L. Z. (2015) 'Pengolahan Limbah Rumah Makan dengan Proses Biofilter Aerobik'. Institut Teknologi Sepuluh Nopember. 
Jurnal Sulolipu : Media Komunikasi Sivitas Akademika dan Masyarakat

Vol. 21 No.2 2021

e-issn : 2622-6960, p-issn : 0854-624X

Tabel 1

Pemeriksaan Suhu dan Limbah Cair Domestik sebelum dan setelah pengolahanTahun 2021

\begin{tabular}{|c|c|c|c|c|c|c|c|c|c|c|}
\hline \multirow{2}{*}{ Parameter } & \multirow{2}{*}{ Sampel } & \multicolumn{8}{|c|}{ Hari } & \multirow{2}{*}{$\begin{array}{l}\text { Rata- } \\
\text { Rata }\end{array}$} \\
\hline & & 0 & 1 & 2 & 3 & 4 & 5 & 6 & 7 & \\
\hline \multirow{2}{*}{ Suhu $\left({ }^{\circ} \mathrm{C}\right)$} & Eksperimen & 32.8 & 31.4 & 31.8 & 32.2 & 32.2 & 32.2 & 31.5 & 30.8 & 31.86 \\
\hline & Kontrol & 31.2 & 29.5 & 30.6 & 27.3 & 27 & 28.5 & 27.5 & 26.3 & 28.49 \\
\hline \multirow{2}{*}{$\mathrm{pH}$} & Eksperimen & 6.72 & 7.15 & 6.85 & 7.27 & 7.19 & 7.34 & 7.89 & 7.09 & 7.19 \\
\hline & Kontrol & 6.82 & 6.87 & 6.85 & 7.33 & 7.85 & 7.76 & 7.82 & 7.74 & 7.38 \\
\hline
\end{tabular}

Sumber : Data Primer

Tabel 2

Pemeriksaan kadar BOD Limbah Cair Domestik sebelum dan setelah pengolahanTahun 2021

\begin{tabular}{|c|c|c|c|c|c|c|c|c|c|}
\hline \multirow{2}{*}{ Sampel } & \multicolumn{8}{|c|}{ Hari } & \multirow{2}{*}{$\begin{array}{l}\text { Penyisihan } \\
(0-7 \text { hari) }\end{array}$} \\
\hline & 0 & 1 & 2 & 3 & 4 & 5 & 6 & 7 & \\
\hline Eksperimen & 186.75 & 83.28 & 63.09 & 43.41 & 24.23 & 11.1 & 8.39 & 6.31 & 97 \\
\hline Kontrol & 186.75 & 160.25 & 129.97 & 98.42 & 79.49 & 60.24 & 45.35 & 29.02 & 84 \\
\hline Standar & 30 & 30 & 30 & 30 & 30 & 30 & 30 & 30 & \\
\hline
\end{tabular}

\section{Sumber : Data Primer}

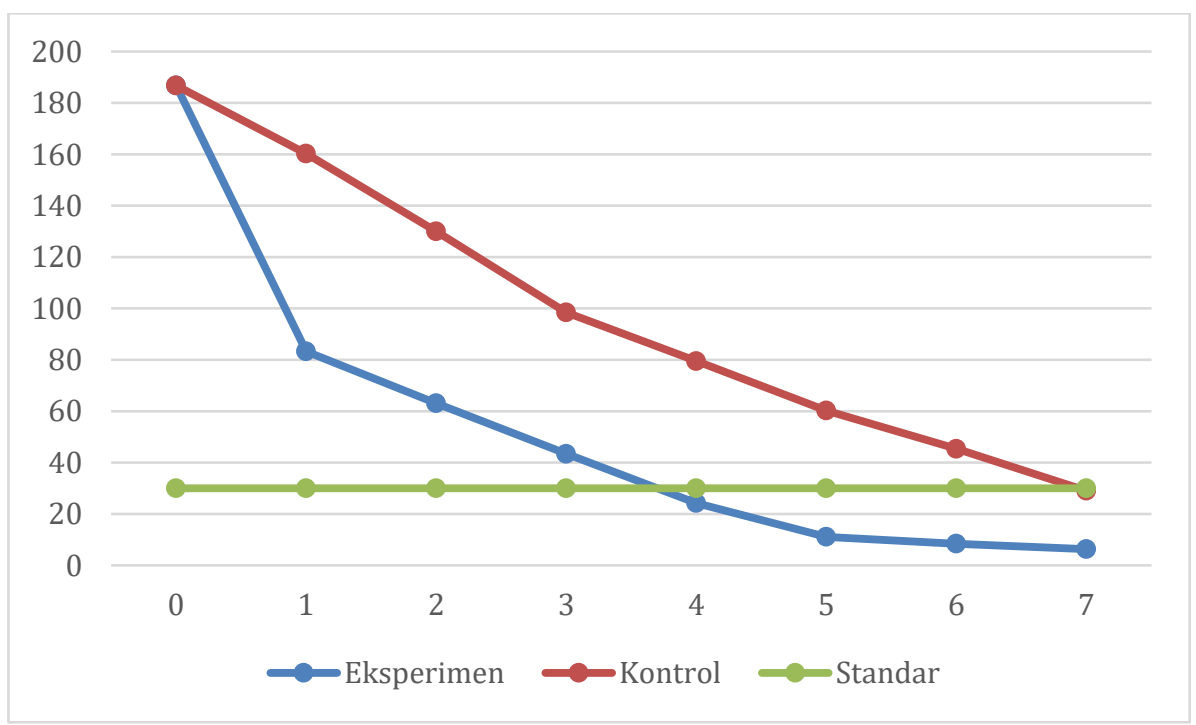

\section{Sumber : Data Primer}

Gambar 1. Grafik Penurunan Kadar BOD pada pengolahan Limbah Cair Domestik 
Jurnal Sulolipu : Media Komunikasi Sivitas Akademika dan Masyarakat Vol. 21 No.2 2021

e-issn : 2622-6960, p-issn : 0854-624X

Tabel 3

Pemeriksaan kadar TSS Limbah Cair Domestik sebelum dan setelah pengolahanTahun 2021

\begin{tabular}{lcccccccccc}
\hline \multirow{2}{*}{ Sampel } & \multicolumn{1}{c}{ Hari } & \multicolumn{1}{c}{ Penyisihan } \\
& \multicolumn{1}{c}{0} & 1 & 2 & 3 & 4 & 5 & 6 & 7 & \\
\hline Eksperimen & 81.65 & 66.65 & 41 & 28 & 22 & 19 & 12 & 3 & 96.32578 \\
\hline Kontrol & 81.65 & 75 & 63 & 52 & 45 & 29 & 25 & 16 & 80.40416 \\
\hline Standar & 30 & 30 & 30 & 30 & 30 & 30 & 30 & 30 \\
\hline
\end{tabular}

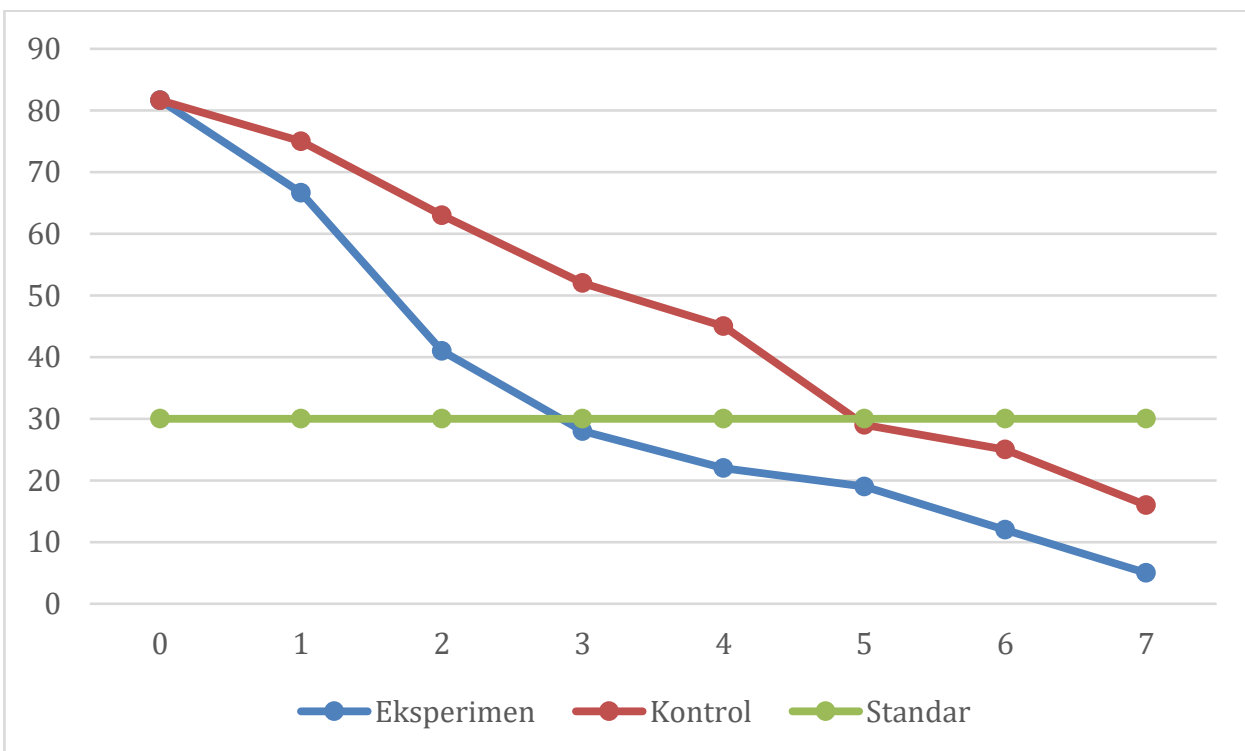

Sumber: Data Primer

Gambar 2. Grafik Penurunan Kadar TSS pada pengolahan Limbah Cair Domestik 